Michelle Unwin \& Belinda Winder 


\title{
A qualitative exploration of the experiences of veterans who are serving sentences in custody.
}

\begin{abstract}
The focus on veterans in research is not a novel topic; however, the majority of studies are related to trauma, employment, mental health, suicide, and substance misuse. The Criminal Justice System involvement with veterans is a topic that has yet to be examined to a great extent. This study, conducted with adult male prisoners, elicited information from six veterans regarding their experiences of being in the armed forces, leaving the armed forces and becoming involved in the Criminal Justice System. Responses were evaluated using Interpretative Phenomenological Analysis (IPA) and three main themes were identified: "you're baptised into the army", 'them and us,' and 'operational mind set'; each of which comprised a number of superordinate themes. The research highlights that, although it is important to acknowledge the heterogenic nature of this group, it is equally important to note that much of their thinking and behaviour may be similar to those that have not had these experiences. As such, there is a need to reduce the notion that they are separate and different to other prisoners, requiring different treatment. The study highlights that many of the Offending Behaviour Programmes and interventions already available to prisoners would be appropriate for this group. The current research supports the merit in creating a service in prisons that will allow for ex-servicemen to meet together and access the support that is available to them. The implications of the research are discussed further.
\end{abstract}

Keywords: veterans, ex-forces, prison, offending, violence, qualitative 


\section{Introduction}

Research suggests that veterans leaving the forces, where they are in a community of strong similarity, for a community in which they may perceive themselves as different, may find it difficult to reintegrate into society (Boyes, 2010). For the majority of people, service in the forces improves life opportunities and, for most, the transition to civilian life is unproblematic. However, for others it can create a range of difficulties and some find they encounter problems such as substance misuse, homelessness and being involved within the criminal justice system (Sayer, et al., 2010; Boyes, 2010).

The training required for someone to join the armed forces makes demands on standards of discipline, consistency, organisation and obedience, which are essential for the situations of conflict that service personnel find themselves in. This can create a protective environment whereby members depend on one another. This can, however, lead to individuals finding themselves in a state of institutionalisation that can cause problems during transition to civilian life (The Howard League for Penal Reform, 2011).

There are a plethora of reasons why someone may leave the armed forces, and an individual may be required to leave at extremely short notice without having the opportunity to plan their transition to civilian life (The Howard League for Penal Reform, 2011). Leaving the services is a significant life change whereby the leaver is required to find employment, accommodation, and build new and existing relationships. If individuals are discharged for disciplinary reasons, they may not receive resettlement provision and for those that do not necessarily want to be discharged this could cause shame and resentment (Elbogen et al., 2012). Individuals leaving within four years of joining have been identified as a particularly vulnerable group with a higher incidence of mental health problems (Iverson et al., 2005). However, those serving over four years have also been found to have experienced a number of problems including mental health difficulties (Crane \& Scott, 2011).

Military service can be a pathway to education, employment and general long term benefits (The Howard League for Penal Reform, 2011). However, serving in the forces, especially at times of conflict, can result in exposure to dangerous and traumatic situations that can cause physical and psychological injuries affecting quality of life (Schnurr, Lunney, Bovin \& Marx, 2009). There are a number of factors that have been linked to reintegration problems in service leavers. One such factor is Post-Traumatic Stress Disorder (PTSD). Studies have identified that veterans with higher levels of PTSD have greater levels of family readjustment problems (Sayers, Farrow, Ross \& Oslin, 2009), employment problems (Schnurr et al., 2009) and poor coping behaviours (Boyes, 2010). Research has also suggested a link between PTSD and crime, with studies finding that the severity of PTSD significantly correlates with disorderly conduct, assaults, driving whilst intoxicated and possession of weapons (Wilson \& Zigelbaum, 1983). PTSD however has been considered to be overrepresented in the veteran population due to people's assumptions that it must be present following exposure to combat or veterans themselves over-reporting their symptoms as they feel this is expected from them (Frueh, Hammer, Cahill, Gold \& Hamlin, 2000). Instead of PTSD, their symptoms may be better matched to diagnoses of anxiety and depression (Crane \& Scott, 2011). This highlights the importance of improving our understanding of the problems that veterans themselves feel they had when leaving the forces. 
Other factors have been found to be of equal or higher prevalence when considering reintegration problems. One of the strongest predictors of problems in reintegration and subsequent imprisonment is substance abuse and dependency (Erickson, Rosenheck, Trestman, Ford, \& Desai, 2008). In a study completed with Iraq and Afghanistan combat veterans, more than half were reported to be struggling with anger problems, and nearly one third had engaged in behaviours that put themselves or others at risk such as dangerous driving, and substance misuse (Sayer, et al., 2010).

According to government figures, the average age of ex-servicemen in custody is older than the average age of the general prison population (The Howard League for Penal Reform, 2011). The figures report that $29 \%$ were over the age of fifty five, which compares to $9 \%$ of the general prison population. The Ministry of Justice statistics (2009) identify that $32.9 \%$ of veterans are in custody for violence compared to $28.6 \%$ of the non-veteran population, and $25 \%$ are in for sexual offences compared to $11 \%$ of the non-veteran population, raising an interesting question as to why this is. There are an increasing number of veterans entering the prison system and it is envisioned that this could increase further as the Armed Forces have recently been removed from Afghanistan. This highlights the need to understand this population further to be able to offer them the support that they may need. Estimates of the proportion of veterans in the prison population vary from 3.5\% to $16.75 \%$ (Brookes, Ashton \& Holliss, 2010; Defence Analytical Services and Advice, 2010; NAPO, 2008).

There are numerous perceptions and assumptions regarding veterans in custody, including that a large proportion of ex-servicemen are in custody because of their military training, combat experience (White, Mulvey, Fox, \& Choate, 2012) and difficulties returning home (Wheeler \& Bragin, 2007). However other perceptions centre on the idea that veterans were troublesome prior to and during their military service (Wainwright, Lennox, McDonnell, Shaw \& Senior, 2016) and therefore their offending was not completely explained by their time in the forces. The armed forces have a history of recruiting school leavers with poor educational attainment, from areas of social deprivation; factors that are linked to higher levels of criminal behaviour (Fossey, 2010). The forces therefore, may have acted as an interlude for those that may have otherwise been involved in crime. This is not the case for all veterans however and as they are a heterogenic group they cannot and should not be classed as all the same.

There has been previous focus on veterans in research, mostly pertaining to their experiences of trauma, employment, mental health, suicide and substance misuse, but also regarding their contact with the criminal justice system (Blonigen et al., 2016). Much of the research that has been completed has been quantitative in nature, such as that which supports the idea that veterans with PTSD show greater levels of violence, anger problems and criminality (Grieger, Benedek, \& Ursano, 2008) and that supporting the link between substance use and offending in the veteran population (Goldberg, 2007).

To date there has been no qualitative research with regard to the perceived experiences of the veterans themselves, and their beliefs around the reasons for their offending and/or their experiences of custody. It was considered that this piece of research would develop insight into veterans accounts of these events and allow for a better understanding of this group of prisoners to be gained. A better understanding of how and why individuals offend, offers the prospect of developing better criminal justice practices (Morgan, 1999; Wilson and Reuss, 2000; Coffey, 2006), and understanding veterans will aid with this further. Interpretative Phenomenological analysis (IPA) was the chosen method of analysis for this research since 
it places the participants as the experts in the topic area, but also allows for the psychological analysis of their narratives, and a connection to extant literature. The purpose of the initial literature review, was to learn about the phenomenon of interest and to identify a gap in what is known about it, but the literature is not subsequently used to inform data collection in a rigid way (Smith, 1999; Smith, Flowers and Larkin, 2009). IPA has previously been used to understand the experiences of men serving a custodial sentence for a sexual offence but who are maintaining their innocence (Blagden, Winder, Thorne \& Gregson, 2011), adult males who have committed sexual offences against elderly female victims (Murphy \& Winder, 2016), men who have downloaded sexually abusive images of children (Winder \& Gough, 2010), male paedophiles who have committed child sexual offences (Blagden, Mann, Webster, Lee \& Williams, 2017) and male prisoners who have participated in peer support schemes (Perring \& Blagden, 2014).

\section{Method}

\section{Participants}

For the purpose of this research a veteran was classed as someone who has served in the armed forces for at least one day (Soldiers, Sailors, Airmen and Families Association (SAFFA)). Participants in the study were male prisoners that had served time in the armed forces and resided in a UK prison.

The sample pool from this UK, category B prison, comprised 887 adult males serving custodial sentences. From this pool, fourteen notifications of interest were received. Upon speaking to each of these potential participants, six of these classed themselves as veterans and the others had mistakenly expressed their interest on the Automated Teller Machine (ATM). The final sample consisted of six participants.

\section{Data Collection}

Ethical approval for the study was obtained from the prison ethics committee and the director of the prison. All prisoners in the establishment were delivered a call for participants information sheet that detailed the aim of the research. The final sample consisted of six participants. Whilst moderate, this was an appropriate sample size for the selected method of analysis (Smith \& Osborn, 2008); moreover, $73 \%$ of the main themes are said to be established during the first six interviews (Guest, Bunce \& Johnson, 2006). The optimal sample size for IPA is one to seven participants as any larger and you could lose the individual richness of the data. Smith et al (2009) highlight that with IPA there must be a commitment to the case study approach and researchers should beware of being pulled into having overly large sample sizes as required with quantitative methods as these can weaken the very strengths of IPA as a method. IPA is not looking to generalise to the population directly but it presents explanatory depth and richness that can often explain quantitative findings. With this study, as with much qualitative research, intensive rather than extensive analysis is what is important. Once interest had been expressed and the six veterans identified, the prisoners were seen by the lead researcher and provided with further information regarding the research. All participants were informed of the restrictions to confidentially within a forensic setting.

All participants were interviewed on a one-to-one basis by the researcher in a private interview room within the establishment. This location offered the participants a private and respectful 
environment to speak. Each interview was recorded on a dictaphone and transcribed verbatim. Following each interview, participants were debriefed, with time allowed for participants to ask any questions.

\section{Interviews}

The data were collected through semi-structured interviews, with a duration of 47 to 130 minutes ( $M=69$ minutes). The interview schedule included prompts relating to different aspects of participants' experiences including:

[1] Experiences of joining the armed forces, being in the armed forces and leaving the armed forces.

[2] Transition from the armed forces into the community.

[3] Offending behaviour.

[4] Experiences of being in custody, including coping abilities and support received.

[5] Plans for release.

\section{Analysis}

The data were analysed using Interpretative Phenomenological analysis (IPA). This method allows for the detailed examination of the participant's world, makes attempts to explore personal experience, and is concerned with an individual's personal perception or account of an event, usually with some personal significance (Smith \& Osborn, 2007). IPA is a hermeneutic method where analysts actively interpret participant accounts by deploying conceptual, psychological language to generate insights into the phenomenon in question. Thus it moves beyond merely describing or re-stating participant terms in order to produce more abstract, theoretical understanding of the topic. IPA is not a predictive methodology as the aim is to explore and learn about a participant's psychological world. Subsequently, no explicit hypothesis was predicted for the study. However, the use of IPA allowed for exploration of the accounts and experiences of veterans serving sentences in custody. IPA allows the participant to tell their story according to what they perceive as salient to them and as such the interviews were primarily led by them, following prompts by the interviewer. The data gained was therefore elicited from a naturally flowing conversation (Pietkiewicz \& Smith, 2012). Analysis involved a number of stages including re-reading the interview transcripts, looking for initial themes that emerged, clustering the themes and matching these meanings to current psychological theory. Several iterative stages of analysis and theming took place, with a constant re-checking and re-grounding back to the transcripts, before the final thematic structure was agreed by the researchers. This iterative process of cross-checking (between researchers) and re-checking (between emergent themes and transcript data) helps to underpin reliability in qualitative research, echoing the techniques of inter-rater reliability and test-retest reliability in quantitative research methods.

\section{Results}

A number of themes emerged regarding the experiences of the veterans that were interviewed. An overview of the themes can be found in table 1 . 
Participants identified a number of factors that they felt connected their time in the army to their subsequent offending behaviour, often relating this to being trained as capable to behave in a certain manner and engage in certain behaviours. Many of the participants discussed how they were not desensitized from this way of thinking and behaving and as such, felt they were still responding to external events as they would have done when in the forces. It was apparent that all of the participants developed a sense of being different to those that had not had the same experiences as them. From this a sense of 'us and them' was deliberated which was apparent both in the community and in custody. As well as this the participants detailed factors relating to the behaviours they present as a result of being trained by the armed forces, such as an overarching respect for authority and the continued need for structure and order.

\section{Superordinate theme 1:}

\section{"You're baptised into the army"}

Participants discussed a sense of being immersed into the armed forces and developing affect, behaviour and cognition that is in line with the process of being a solider and being trained to fight the enemy and protect one's self. Participants discussed being "turned from a civilian into a solider" (P2). Review of the transcripts highlighted that many of the participants had become "desensitised" to the use of violence. As such without any formal way of changing this they highlighted how this imbedded way of thinking had continued upon being discharged.

\section{Violence is normal}

Participants highlighted some normalised attitudes about violence which presented as relating to their acceptability of its use and minimisation of it in specific contexts:

P5: "I broke his fingers and cut his ears and stuff, I don't class it as a lot of violence what I did to him"

Several studies support the idea that normalised beliefs about violence are associated with actual violent behaviour towards other individuals (Dodge et al., 2006). The presence of such beliefs has been shown to be important in regulating aggressive behaviour and in determining people's reactions to 'harmful' incidents (Pepitone, 1981). This normalisation of violence was present in the above extract relating to the participant's index offence where although extreme violence was used it was not felt as such by the individual.

Other participants presented the notion of violence being normal in that they felt that their behaviour was justified:

P3:"I was like twenty two and he was like twenty eight at the time and he was going for me and like anybody else in the world, I hit him, I wasn't scared of him, I've been shot at by snipers and skimmed by bullets, threat was expected"

When P3 explained the situation relating to the above quote, it was evident that he was not under actual threat and as such perceived a potentially non-hostile situation as being hostile. As highlighted by this extract the participants were in a state of expecting threat as they had been when in the armed forces. It was apparent that as would be the case when acting to protect oneself from a known enemy, the participants continued to attribute the actions of others to be hostile and as such, continued to respond based on this way of thinking. The theory of Attribution Bias (Heider, 1958) is a useful theory to explain such thinking and refers 
to errors made when people try to find reasons for others' behaviours which do not always accurately mirror reality. As such, the threat that was "expected" by participant 3 may have not been accurate but has still guided his responses. Similar to what is described in much of the literature pertaining to learnt history and offending behaviour, the Social Learning Theory (Bandura, 1977) would suggest that an individual is more likely to continue to use certain behaviours if they are rewarded for these. As a soldier, part of the reward for using violence could be a sense of achievement in undertaking your job, survival and protection of your country and those that you are serving with. These present as quite substantial reasons for using violence in this setting and can lead to this way of thinking becoming normalised. The Social Information Processing Theory of Aggression (Huesmann, 1998) suggests that individuals have mental 'scripts' which sequence how they should behave based on their learning. These scripts become automatic over time through rehearsal which can make them resistant to modification. Of additional importance within this theme is the theory of Hostile Attribution Bias (Barron \& Richardson, 1994). Hostile attribution bias can be learnt from seeing a stimulus that is hostile and being trained to respond to this accordingly. This way of thinking can then carry on and lead to a person seeing the world as a hostile place (Shrum, Burroughs \& Rindfleisch, 2004). To put into context with this theme; being in the armed forces has taught individuals to believe that when in active combat, rightly, the actions of others may be hostile. This way of thinking, however, can continue after being in the forces and as such, when presented with negative cues can lead to hostile actions. All participants identified a lack of "desensitisation" from this way of thinking upon returning to the community, which many attributed as the reason they continued to think and behave as a solider may do.

\section{Military operation}

The term "military operation" was used by participants in the study when sharing their actions within their offending behaviour. The participants described their capabilities as being associated with the intensive training received when they were in the armed forces and from this explained how they were better equipped to commit their offences. Participant three described himself as being a "trained killer" who upon leaving the forces was not rid of this engrained response to hostility. He linked this to his offence which he detailed would not have occurred if he did not have this ability to "respond as a killer".

P3: "I reacted to things differently, like on the farm l'd go out shooting with them and everyone would be normal and l'd be ready for combat, like I was still in the army.... I just went into autopilot, all it took was for her to run at me and I loaded my gun and shot her"

This theme emerged not purely from being trained to kill but also from the participants' use of the skills gained to assist in other offending behaviours:

P4: "There were three of us exporting the drugs, we were all ex forces and the way we worked, taking notes and observing and doing surveillance, it was like a military operation"

P2: "There is an ethos in the army that if you are going to do something then do it properly; fires are good killers of everything"

P1: "The army taught me to escape and be persistent in not getting caught by the police, dogs and helicopters" 
Here the participants detail how they were able to use their training to benefit themselves either in committing their criminal offences or avoiding detection. P4 details how he and other veterans were working together, using the skills they learnt, to plan and undertake the exportation of illegal substances, highlighting again the use of the training to assist in criminal activity. Much of what the participants discussed with regards to their offending was not dissimilar to that which is discussed by other offenders, especially relating to evading detection and offending with others. The difference here is the offenders in this research significantly linked their offences to their military experience rather than any other predisposing factors.

\section{Yearning for excitement}

The participants all displayed a sense of regret at leaving the forces, recalling it as being a positive time of their lives. A theme ran through the data that pertained to the participants missing the lifestyle that they lived when serving in the forces and many detailed a life in the community that "lacked excitement and thrill" that they would achieve when "on tour".

\section{P4:"I just yearned for the excitement that I did not have when I left the army"}

P2: "Drugs gave me that rush that I used to get in the army that I no longer got. It was difficult for me to work in a company as there was no thrill and no excitement, life got boring"

One of the strongest predictors of problems in reintegration and subsequent imprisonment has been found to be alcohol and drug abuse and dependency (Erickson et al., 2008). As detailed in participant two's quote, he attributed his drug addiction to be a result of a need for thrill that he felt he no longer gained in the community. Thrill seeking, also termed as sensation seeking, is a personality trait expressed in the generalised tendency to seek novel, complex, and intense sensations and experiences and the willingness to take risks for the sake of such experiences (Zuckerman, 2007). There is considerable evidence that thrill seekers are at increased risk for using drugs and engaging in offending behaviour (Bardo, Donohew \& Harrington, 1996; Knust \& Stewart 2002). It appeared from the participants' descriptions that this need for thrill and excitement originated from being in the armed forces but if it is considered that thrill seeking behaviour is a personality trait, it may in fact be that this was the reasons they joined the armed forces in the first place and this continued upon discharge.

\section{Superordinate theme 2}

\section{Us vs them}

A narrative thread that emerged through the transcripts related to the participants seeing themselves, or feeling that they were different to others that had not served in the forces. In some respect this presented as being quite hostile to others that had not experienced what they had, whereas for others it related to an individual's need to belong to something that they may not have had the opportunity to have done before.

\section{A different mindset}

The participants described themselves as being different to other members of the community and other prisoners in the establishment. This belief that they thought and behaved differently resulted in at times quite poor opinions of others and the sense of being superior to someone that had not served in the forces. 
P3: "we've probably all got the same attitude, it's all the same, it's kind of like a clique, it's kind of like we all had a clique and that's where I met my best friends... we've lived in similar situations on camp and that's probably why l've got this attitude to want to work rather than waste away like some of these losers"

P2: "it wasn't until l'd done programmes that I realised that my thinking was different to everyone else, you're not given time to think in the army and you think on impulse"

P5:"I think talking to other veterans would give me the opportunity to feel more comfortable and talk to people with the same discipline and same mind-set, instead of half of these layabouts in here"

P4: "they haven't had the same experiences as us, you have friends in the army that you rely on so much and you come out here and they just don't understand"

Participant four describes how individuals who have not been in the forces "don't understand" the experiences of those who have served in the armed forces. Although this is probably the case for most, many of the participants discussed how this was a barrier to effective reintegration. They discussed that upon leaving the forces they were not spending time with people who had experienced what they had and as such felt unable to find solace in those that had not served in the forces. Participant 4 described how due to his family and friends not having these experiences he became 'resentful' when they tried to understand what he 'was going through' and as a result pushed them away when they tried to support him. It appears that having a different mind-set potentially restricts participants integrating within the community. This is because they see themselves as different to others who have not been subject to the same experiences as them, and therefore have a different identity. Social identity is an individual's self-concept of their membership of social groups which defines them as being different to other groups (Hogg \& Vaughan, 2002). Social Identity Theory (Tajfel \& Turner, 1979) asserts that group membership creates a sense of an in-group categorisation. This can lead to members of the in-group favouring themselves at the expense of the outgroup (Turner \& Tajfel, 1986). As can be noted in participant three's extract; he deems those in the out-group to be "losers" and as such, favouritism can be seen in the way he speaks about those that have served in the forces compared to those that have not.

\section{Need for belonging}

Research has suggested that leaving the strong community that is present in the armed forces can cause difficulties in a person's reintegration into society (Wheeler \& Bragin, 2007). Participants highlighted this difficulty and described experiences of losing their sense of belonging that was present in the forces.

P2:"civvy street didn't really offer me that belonging that I enjoyed as l'd never been in a family and when I left I just yearned for it"

P4: "I felt that I belonged somewhere- I was part of the furniture, it was nice and gave me the reassurance I needed"

Losing this sense of belonging seemed integral in participants' experiences and difficulties of leaving the armed forces. The majority of participants detailed the sense of belonging to be a fundamental part of enjoying their time in the forces and something that they did not achieve 
when in the community, and which has been linked to offending behaviour (Wainwright et al., 2016). Some participants expressed that this was due to an upbringing where this sense of belonging had never been present, whereas others had a sense of belonging already but felt it was not as strong as that developed in the forces. Tajfel and Turner (1979) proposed that groups which people belonged to were an important source of pride and self-esteem. Groups, such as those formed in the armed forces, can give individuals a sense of social identity and a sense of belonging to the social world which appeared present in participants' accounts.

\section{Camaraderie}

Camaraderie was discussed as an important attribute of being a soldier by all of the participants. The sense of companionship presented as an experience that was deemed to be positive and natural in the environment that the participants were in.

P2: "there's just a sense of camaraderie, you're just together, you don't even need to ask and the next man has got your back and you have theirs"

P3: "I had this mad sense of self-sacrifice about putting my friends before myself, my attitude out there was that I would take a bullet for my mate- l'd put them before me"

The participants described camaraderie as a vital attribute of being in the armed forces and as such this was spoken about with affection but also distress due to the absence of this when they left the armed forces. With this camaraderie being missed it was apparent, from review of the transcripts, that the participants still had a desire for this and as such strived for solitude in other prisoners that had served time in the armed forces. This is in line with Tajfel and Turner's (1979) Social Identity Theory whereby this desire to be with those that you may feel companionship with allows for a person to maintain their sense of who they are.

\section{Superordinate theme 3}

\section{Operational mind-set}

The participants described in detail the experiences of being trained to be a soldier and how this transpires in them as an individual. A distinction of what a soldier is and how this presents in behaviour and attitudes in the forces, the community, and in prison was clear throughout the interviews. Training to be in the armed forces is extensive and the participants detailed it as being a "testing but rewarding experience". Such extensive training creates individuals that are designed to act alike and be independent yet protect others and this was apparent in the descriptions provided by the participants.

\section{Obedience to authority}

All participants expressed a desire to be obedient to authority which they felt was a result of being in the armed forces. Obedience to those of above ranks in the army is vital and as such the participants seemed to have applied this way of thinking to their ability to work with the staff within the custodial setting.

P5:"I get on really well with [prison] officers, if they tell me to do something then I will do it, maybe that's why people have problems with me as if an officer says do whatever I'll do it and wont deviate from that" 
P6: "prison is very similar to the army, yes sir, no sir, [prison] officers sort of pick up on that as we are quite accepting of authority"

P2:"if I hadn't have been in the army I would have been more belligerent to authority, I understand authority and the ranking more than someone else would"

P3:"if people tell me what to do and they don't have stripes then I don't like that, I don't respect them, [prison] officers are in charge, I can accept that"

The sense of respect for authority ran through all of the transcripts and was evidently something that made it easier for the participants to manage their custodial sentence. Participant three describes a distinction with how he views authority to other members of the public, something that has clearly been a learnt response in the army as he refers to them as "stripes". This does raise interest and provides a link with the theme of 'us and them' in that he cannot respect those that are not in this superior group.

\section{Structure and order}

All participants detailed a developed need for structure and order, something that is an important aspect of being in the armed forces. This was described as a positive attribute that was learnt and something that the participants felt they wanted to keep.

P5: "I need discipline and order and that's why I should have stayed in the army, my cell is always clean and I get up every morning on time and stuff, as it taught me structure"

P2:“Civvy street didn't offer me that structure and I yearned for it when I left, I needed direction and order and that's what the army gave me"

The above extracts detail how this structure and order made the participants regret leaving the forces as it was deemed of such importance. It appeared that this part of being a soldier is something that both guided the participants to join the armed forces and helped them to cope with the regime of a prison environment. Responding to the supervision that the custodial environment offers can be challenging for individuals and as such many prisoners fail to comply with rules and regimes imposed in such a setting (Douglas, Hart, Webster \& Belfrage, 2013). These challenges did not seem to be something that the participants faced and it would be perceived that they found the custodial environment offered structure that may not have been available in the community after leaving the armed forces.

\section{“I shouldn't be asking for help"}

A narrative thread that emerged through the transcripts related to the level of support accessed by the participants. At first it was apparent that the participants did not feel they received enough support upon leaving the forces. From further analysis it emerged that in fact the majority of the participants did not want or did not feel that they should be asking for help as demonstrated in the extracts below:

P2: "You're told to basically put up with it unless your arm is like breaking off they tell you to just get on with it, they'd rather get you out and let civvy street deal with you but it can be too late then" 
P2: "I didn't really even do anything, I haven't been in a war zone for years, so I did not feel I was entitled to help"

P3:"I didn't need help, well I thought I didn't need it, I didn't really want it, if someone would have said come on we are going to get you help I would not have cooperated"

As such this flowed through the transcripts and when the participants should have been accessing help they chose not to; even at times when it was offered. This view of help-seeking behaviour in men in general is evident in research and studies have reported that men who step outside typical gender constructions relating to help-seeking tended to be marked as deviant to others (Seymour-Smith, Wetherell \& Pheonix, 2002). Literature pertaining to men's health highlights how although young men may want to seek help they have a desire to maintain masculine identities surrounding independence, autonomy and control (Tyler \& Williams, 2013). Thus, this seems to be a characteristic of men in terms of their help-seeking behaviour, but the analysis of this dataset indicates that serving in the armed forces exacerbates this characteristic - veterans are expected to 'get on with it', meaning they are even less likely than a typical male to admit they need help and to take the next step of asking for this support, even when it is offered and needed. This has implications for the uptake of a range of resources by veterans (e.g. counselling and therapy for PTSD), and accordingly potential implications for further offending (where problems, such as substance abuse or trauma, are left untreated).

\section{Discussion}

The study has extracted a number of themes that allow for a better understanding of the experiences of veterans in custody to be gained. The findings show that the participants felt that they were "baptised" into the armed forces which changed the way they approached situations based on a new way of perceiving the world around them. As might be expected, to serve in the armed forces, especially in times of conflict, you would need to be prepared to use violence and be aware of potential threats. The problem seems to be that upon leaving the forces, this way of thinking does not necessarily discontinue and there is a lack of available intervention to change this imbedded way of thinking. A number of studies support the idea that normalised beliefs about violence in particular are associated with actual violent behaviour towards other individuals (Dodge et al., 2006). With many of the participants it was apparent that this normalisation of violence had contributed in part to their responses to situations when in the community.

Offending Behaviour Programmes delivered at present in the prison and probation services are predominantly based on a Cognitive Behavioural Model which works on the notion that there may be problems in an individual's cognition that allows them to engage in criminal activity. The implications that have been drawn from the participants' accounts would suggest that they would benefit from accessing these programmes. This would allow for the mental scripts that have developed to be challenged and where necessary alterations in their experience of cognition, affect and behaviour to be made. Although this offers an opportunity for them to make necessary changes, it is unfortunate that this has to occur after an offence has been committed rather than before. All participants made reference to the lack of help they were offered to support the process of "desensitisation" following leaving the forces and many attributed this in part to their offences been committed. The research therefore identifies the benefits that could be gained if individuals were provided with intervention upon discharge 
to ensure that they are prepared to reintegrate. This would give individuals the opportunity to change their cognitions that contribute to hostile attribution being applied to others' actions in the community. It will also provide them with skills to manage difficulties they may encounter upon discharge and help prevent them from using their training to undertake criminal activity.

Of interest in the findings from this research is that the drug use that was reported was a result of thrill seeking behaviours rather than a method of coping with difficulties. Previous studies in support of this found that a third of Iraq and Afghanistan combat veterans had engaged in behaviours that put themselves or others at risk, such as drug use (Sayer et al., 2010) and there is considerable evidence that thrill seekers are at increased risk for using drugs (Bardo et al., 1996). Thrill seeking is identified as being a personality trait (Zuckerman, 2007) and has also been linked to offending behaviour (Knust \& Stewart 2002). The current research has not explored links between thrill seeking behaviour and offending behaviour or reasons for joining the armed forces. This may be an area in need of further research in the future as it would allow for a deeper understanding to be gained regarding whether a sensation seeking personality is important in the experiences of veterans and the problems that they may encounter upon discharge.

Perhaps unsurprisingly, the notion of camaraderie was a theme that was extracted from the data but what was interesting was the extent of the "them and us" way of seeing the world. The participants detailed how they saw themselves as being different to others that had not served in the forces and the feeling of being different at times presented in a hostile description of others. The sense of camaraderie that is developed in the forces would likely create a strong sense of group identity which in itself could have benefits as a 'social cure', whereby feeling part of a group has been shown to have positive mental health benefits, even (or especially) in extreme conditions (Kellezi \& Reicher, 2012). As evident from the analysis; the identity that is formed is one in which protection and trust of one another is paramount. This identity is not one which in normal circumstances would cause concern, however the view of those not in the in-group could be deemed to be more problematic and evidently leads to discrimination against those deemed to be in the out-group. There is merit in creating groups in custody that allow for individuals that have served in the forces to come together in a social context. Tajfel and Turner (1979) outlined that groups where people feel they belong are an important source of pride and self-esteem. There are a number of projects present in the prison service that allow for this, including the Veterans In Custody Support (VICS) project which ensures that veterans are aware of the specialist help and support they are entitled to. It is important however, that when developing these groups and allowing for social networking, the members are discouraged from discriminating against those that have not served in the armed forces. As such, efforts should be made to challenge such behaviours and encourage a more inclusive mindset which will help them to integrate into wider society more effectively. It is important that people are able to transition onwards from a previous identity that has negative connotations for them (or for others) to an identity that they are comfortable with but which allows them to grow and develop in a pro-social manner (Best, et al., 2016).

A theme that transpired from the research which has been supported in previous literature is the idea that the participants did not feel that they should ask for help and did not want to access support. One of the problems evident from the literature review is the reluctance of exservicemen to take advantage of the help available. Research suggests that they do not seek help because of the stigma attached to this (Hoge et al., 2004). Although terminology such as 'stigma' was not used by the participants, it was evident that they did not feel they were entitled 
to help and had been taught to think that they should not request it. It seemed that due to being taught this the participants were then unwilling to accept it and see the merits of it. Therefore creating projects with the word 'support' in may actually deter veterans from approaching the service and accessing the help that it can offer. Instead it would be recommended that projects designed to assist veterans take out the word 'support' and offer it more as a service for them to meet with other veterans who can assist one another. Within these groups, individuals should be reassured about why asking for help is not a sign of vulnerability, and role models (other veterans) could be used to encourage them to be open to seeking help. Positive role models with referent authority (French, Raven \& Cartwright, 1959) of the group, would be a helpful way of helping people move towards support .To assist in making these projects successful it would also be advised that any individual that identifies themselves as someone that has served in the armed forces be given information relating to the available support and seen individually by a member of the service team. This would eradicate the need for them to ask for the support and subsequently may lead to a more successful veterans service been implemented.

\section{Limitations}

It is important to acknowledge the limitations of this study. As with any qualitative methodology the study relies on self-report from the prisoners and this may involve self-presentational biases. One participant in particular was more resistant to providing information that he thought may have led him to be seen in a negative light and as such the wealth of information gained from him may have been restricted. Although the sample size was moderate, it was appropriate for the chosen method and additionally, the researchers concluded that the data has reached a level of saturation. It is important to acknowledge that there were many more veterans in the prison establishment than those who volunteered to participate in the research. The self-selection bias, in this instance, could reflect factors such as more pro-social leanings, perhaps indicative of a post-treatment sample. Alternatively, it could indicate individuals who felt more shame or embarrassment about their predicament, or felt that being a known British veteran could place them at risk from those in the prison service that have problems with such individuals, such as those that identify with political and religious groups that are against the British Army. It would be useful to be able to compare participating veterans with nonparticipating veterans, however this was unfortunately outside the scope of this study.

Qualitative research does not seek to generalise in the same way that quantitative research aims to, instead relying on embedding the emerging themes within the established literature. However, the authors would nevertheless reiterate that all research should maintain an approach that acknowledges individual diversity whilst reporting meaningful patterns within data.

\section{Conclusions}

The findings from this research allow for insight to be gained into the experiences of veterans that are currently serving sentences in custody. This area is novel and as such the analysis has presented some of the only qualitative results that develop our insight into this heterogeneous group of prisoners. There is often a misconception that the reason veterans may offend is due to PTSD, however this is considered to be overrepresented in the veteran population (Frueh et al., 2000). In the current study, only one of the participants reported experiences of trauma symptoms after leaving the forces. Recent research (Elbogen et al., 
2012) has supported this and identified that clinicians should also consider non-PTSD factors when evaluating and treating veterans with criminal justice involvement. It is important to highlight the heterogenic nature of this group and the different experiences that they may have encountered prior to prison. However, equally it is important to note that much of their thinking and behaviour may be similar to those that have not had these experiences and as such there is a need to reduce the notion that they are separate and different to other prisoners and therefore need different treatment. The 'us and them' perception can then potentially be reduced which could assist in better communication and less hostile thinking patterns towards others.

\section{References}

Bandura, A. (1977). Social learning theory. Englewood Cliffs, NJ: Prentice Hall.

Bardo, M., Donohew, R. L., \& Harrington, N. G. (1996). Psychobiology of novelty seeking and drug seeking behaviour. Behavioural Brain Research, 77, 23-43.

Barron, R. \& Richardson D. (1994). Human aggression. New York: Plenum press.

Best, D., Beckwith, M., Haslam, C., Alexander Haslam, S., Jetten, J., Mawson, E., \& Lubman, D. I. (2016). Overcoming alcohol and other drug addiction as a process of social identity transition: The Social Identity Model of Recovery (SIMOR). Addiction Research \& Theory, 24(2), 111-123.

Blagden, N. J., Mann, R., Webster, S., Lee, R., \& Williams, F. (2017). “It's Not Something I Chose You Know": Making Sense of Pedophiles' Sexual Interest in Children and the Impact on Their Psychosexual Identity. Sexual Abuse, 1079063217697132.

Blagden, N. J., Winder, B., Thorne, K., \& Gregson, M. (2011). 'No-one in the world would ever wanna speak to me again': an interpretative phenomenological analysis into convicted sexual offenders' accounts and experiences of maintaining and leaving denial. Psychology, Crime \& Law, 17(7), 563-585.

Blonigen, D. M., Bui, L., Elbogen, E. B., Blodgett, J. C., Maisel, N. C., Midboe, A. M., ... \& Timko, C. (2016). Risk of recidivism among justice-involved veterans: A systematic review of the literature. Criminal justice policy review, 27(8), 812-837.

Boyes, P. (2010). Remembering the veterans. The Psychologist, 23(11), 940-941. 
Brookes, M., Ashton, C \& Holliss, A. (2010) 'Assisting Veterans at HMP Grendon and Springhill'. Prison Service Journal, 190, 3-9.

Coffey, M. (2006). Researching service user views in forensic mental health: A literature review. The Journal of Forensic Psychiatry \& Psychology, 17(1), 73-107.

Crane, M \& Scott, H (2011) Veterans in Custody: A small scale needs analysis. Forensic Update 103- Summer 2011. The British Psychological Society.

Defence Analytical Services and Advice. (2010). UK Defence Statistics 2010. Retrieved from www.dasa.mod.uk

Dodge, K. A., Coie, J. D., \& Lynam, D. (2006). Aggression and antisocial behavior in youth. In Damon, W., Lerner, R. M., \& Eisenberg, N. (Eds.), Handbook of child psychology, vol. 3. (pp. 719-776) New York: John Wiley \& Sons.

Douglas, K. S., Hart, S. D., Webster, C. D., \& Belfrage, H. (2013). HCR-20 (Version 3): Assessing Risk for Violence. Burnaby, BC, Canada: Mental Health, Law, and Policy Institute, Simon Fraser University.

Elbogen, E. B., Johnson, S, C., Newton, V, M., Straits-Troster, K., Vasterling, J, J., Wagner, H, R., \& Beckham, J, C. (2012). Criminal justice involvement, trauma, and negative affect in Iraq and Afghanistan war era veterans. Journal of Consulting and Clinical Psychiatry, 80(6), 1097-102.

Erickson, S, K., Rosenheck, R, A., Trestman, R, L., Ford, J, D., \& Desai, R, A. (2008) Risk of incarceration between cohorts of veterans with and without mental illness discharged from inpatient units. Psychiatric services, 59 (2), 178-183.

Fossey, M. (2010). Across the Wire. Veterans, Mental Health and Vulnerability. Centre for Mental Health. 
French, J. R., Raven, B., \& Cartwright, D. (1959). The bases of social power. Classics of organization theory, 7.

Frueh, B.C., Hamner, M.B., Cahill, S.P, Gold, P.B., \& Hamlin, K.L. (2000). Apparent symptom over reporting in combat veterans evaluated for PTSD. Clinical Psychology Review, 20, 853-885.

Goldberg, D (2008). Analysis of coping to mediate trauma and violence in male military veterans (Doctoral dissertation).

Grieger, T. A., Benedek, D. M., \& Ursano, R. J. (2008). Posttraumatic stress disorder. In R. I. Simon \& K. Tardiff (Eds.), Textbook of violence assessment and management. Arlington, VA: American Psychiatric Publishing, Inc.

Guest, G., Bruce, A., \& Johnson, L. (2006) How many interviews are enough? An experiment with data saturation and variability. Field Methods. 2006;18(1):59-82. 27.

Heider, F. (1958). The psychology of interpersonal relations, New York: Wiley.

Hoge, C.W., Castro, C.A., Messer, S. C., McGurk, D., Cotting, D. I \& Koffman, R. L. (2004). Combat Duty in Iraq and Afghanistan, Mental Health Problems and Barriers to Care. The New England Journal of Medicine, 351, 1, 13-22.

Hogg, M.A. \& Vaughan, G.M. (2002). Social Psychology. London: Prentice Hall.

Huesmann, L. R. (1998). The role of social information processing and cognitive schema in the acquisition and maintenance of habitual aggressive behaviour. In R. Geen \& E. Donnerstein (Eds.), Human Aggression: Theories, research, and Implications for Social Policy (pp. 73-109). New York: Academic Press.

Iverson, A., Dyson, C., Smith, N., Greenberg, N., Walwyn, R., Unwin, C., Hull, L., Hotopt, M., Dandeker, C., Ross, J., \& Wessely, S. (2005). Goodbye and good luck: the mental 
health needs and treatment experiences of British ex- service personnel. The British Journal of Psychiatry, 186, 480-486.

Kellezi, B., \& Reicher, S. (2012). Social cure or social curse? The psychological impact of extreme events during the Kosovo conflict.

Knust, S, \& Stewart, A, L. (2002) Risk-taking behaviour and criminal offending: an investigation of sensation seeking and the Eysenck personality questionnaire. International Journal of Offender Therapy and Comparative Criminology. 46(5), 586602.

Ministry of Justice. (2009). Population in custody monthly tables. London: Ministry of Justice.

Morgan, S. (1999) 'Prison lives: critical issues in reading prisoner autobiographies', Howard Journal, 38, 328-40.

Murphy, R., \& Winder, B. (2016). 'If you'd had my life, you'd have done it too': exploring the experiences of adult males who rape elderly females. Psychology, Crime \& Law, 22(8), 798-816.

Napo (2008) Ex Armed Forces Personnel and the Criminal Justice System, London, Napo.

Pepitone, A. (1981).The normative basis of aggression: Anger and punitiveness. Recherches de Psychologie Sociale, (3), 3-17.

Perrin, C., \& Blagden, N. (2014). Accumulating meaning, purpose and opportunities to change 'drip by drip': the impact of being a listener in prison. Psychology, Crime \& Law, 20(9), 902-920.

Sayer, N. A., Noorbaloochi, S., Frazier, P., Carlson, K., Gravely, A., \& Murdoch, M. (2010). Reintegration problems and treatment interests among Iraq and Afghanistan combat veterans receiving VA medical care. Psychiatry Services, 61 (6), 589-597. 
Sayers, S. L., Farrow, V. A., Ross, J., \& Oslin, D. W. (2009). Family problems among recently returned military veterans referred for a mental health evaluation. Journal of Clinical Psychiatry. 10, 1-18.

Schnurr, P, P., Lunney, C, A., Bovin, M, J., \& Marx, B, P. (2009). Posttraumatic stress disorder and quality of life: extension of findings to veterans of the wars of Iraq and Afghanistan. Clinical Psychology Review. 29, 727-735.

Seymour-Smith, S., Wetherell, M., \& Pheonix, A. (2002). 'My wife ordered me to come!': A discursive analysis of doctors' and nurses' accounts of men's use of general practitioners. Journal of Health Psychology. 7, 253-267.

Shrum, L. J., Burroughs, J. E. \& Rindfleisch, A. (2004). A process model of consumer cultivation: the role of television is a function of the type of judgement. In L. J. Shrum (Ed.), The psychology of entertainment media: Blurring the lines between entertainment and persuasion (pp. 177-191). Mahwah, NJ: Erlbaum.

Smith, J, A. (1999). Towards a relational self: social engagement during pregnancy and psychological preparation for motherhood. British Journal of Social Psychology 38, 409-426.

Smith, J. A., Flowers, P., \& Larkin, M. (2009) Interpretative phenomenological analysis: theory, method and research. Los Angeles, Sage.

Smith, J.A., \& Osborn, M. (2008). Interpretative Phenomenological Analysis. Pain as an assault on the self: An interpretative phenomenological analysis. Psychology and Health, 22, 517-534.

Tajfel, H., \& Turner, J. C. (1979). An integrative theory of intergroup conflict. The social psychology of intergroup relations, 33, 47. 
Turner, J. C. \& Tajfel, H. (1986). The social identity theory of inter-group behavior. In S. Worchel and L. W. Austin (Eds.), Psychology of Intergroup Relations. Chicago: NelsonHall.

The Howard League for Penal Reform. (2011). Report of the Inquiry into Former Armed Service Personal in prison. Retrieved from www.howardleague.org

Tyler, R. E., \& Williams, S. (2013). Masculinity in young men's health: Exploring health, helpseeking and health service use in an online environment. Journal of Health Psychology, 19, 457-470.

Wainwright, V., Lennox, C., McDonnell, S., Shaw, J. \& Senior, J. (2016). Offending Characteristics of Male Ex-Armed Forces Personnel in Prison. The Howard Journal of Crime and Justice. DOI: 10.1111/hojo.12189

Wheeler, D. P., \& Bragin, M. (2007). Bringing it all back home: Social work and the challenge of returning veterans. Health \& Social Work, 32(4), 297-300.

White, M. D., Mulvey, P., Fox, A. M., \& Choate, D. (2012). A hero's welcome? Exploring the prevalence and problems of military veterans in the arrestee population. Justice Quarterly, 29(2), 258-286.

Wilson, D., \& Reuss, A. (2000) Prison(er) Education: Stories of Change and Transformation. Winchester: Waterside Press.

Wilson, J. P., \& Zigelbaum, S. D. (1983). The Vietnam veteran on trial: The relation of post traumatic stress disorder to criminal behaviour. Behavioural Sciences and Law, 1, 69-83.

Winder, B., \& Gough, B. (2010). "I never touched anybody—that's my defence": A qualitative analysis of internet sex offender accounts. Journal of Sexual Aggression, 16(2), 125141. 
Zuckerman, Marvin (2007). "The sensation seeking scale V (SSS-V): Still reliable and valid". Personality and Individual Differences 43 (5): 1303-1305. 